\title{
PERAN KEPALA SEKOLAH DALAM AKTUALISASI MANAJEMEN PENINGKATAN MUTU BERBASIS SEKOLAH (MPMBS) DI SMP NEGERI 13 MALANG
}

\author{
Rr. Kusuma Dwi Nur Ma'rifati'1, Fahrur Rosikh² \\ Institut Agama Islam Nahdlatul Ulama Tuban'1 Institut Pesantren Sunan Drajat Lamongan² \\ Email: kusumanur69@gmail.com¹, frrosikh@gmail.com
}

Dikirim: 6 Juli 2020 | Direvisi: 17 Juli 2020 | Dipublikasikan: 31 Juli 2020

\begin{abstract}
Abstraksi: Iklim birokratisasi dalam dunia pendidikan begitu kental, terbukti dengan begitu dominannya penguasa dalam pengambilan kebijakan pendidikan. Ironisnya kebijakan yang diambil terjadi tumpang tindih khususnya kebijakan yang dulunya sentralistik bermasalah pada kebijakan otonomi pendidikan. Sehingga berpengaruh pada peningkatan mutu satuan pendidikan. Adanya tumpang tindih kebiajakan berpengaruh pada kebijakan yang dilakukan pemimpin lembaga, dalam hal ini kepala sekolah. Karena, maju mundurnya sebuah institusi sangat dipengaruhi oleh kebijakan kepala sekolah. Sehingga dapat dikatakan bahwa peran kepala sekolah begitu signifikan dalam melaksanakan program-program yang nantinya akan berdampak kepada mutu satuan pendidikan. Fokus artikel ini mencoba memotret bagaimana peran kepala sekolah dalam MPMBS di SMPN 13 Malang. Metode yang digunakan adalah studi kasus dengan pendekatan kualitatif. Pengumpulan data melalui observasi, wawancara dan dokumentasi. Hasil penelitian menjelaskan adanya pemahaman konsep MPMBS dengan baik, dengan ditunjukkan kinerja kepala sekolah yang telah mengarah pada pengembangan visi sekolah yang realistis dan rasional. Peran yang dilakukan dalam aktualisasi MPMBS yakni sebagai: (a) manajer: dengan membuat perencanaan, pengorganisasian, menggerakkan warga sekolah serta mengawasi pelaksanaan peningkatan mutu sekolah. (b) pendidik: meningkatkan kualitas guru dengan mengirim mengikuti pelatihan, seminar, dan MGMP. Serta meningkatkan prestasi siswa dengan menambah jam pembelajaran, mengadakan try out, dan mengembangkan ekstrakurikuler (c) supervisor: melakukan pengawasan dan pengendalian dalam meningkatkan kinerja PTK dan menyelesaikan permasalahan guru secara baik; (d) pemimpin: melibatkan warga sekolah dalam pengambilan kebijakan. Dari hal diatas dalam implementasi MPMBS direkomendasikan pentingnya kepala sekolah yang berkemampuan, kemauan dan komitmen yang tinggi kearah kemajuan sekolah yang berorientasi pada kemajuan IPTEK agar tercapai sebuah visi yang telah direncanakan secara maksimal.
\end{abstract}

Kata kunci: Kepemimpinan ; Manajemen; Mutu; Peran; Sekolah.

\section{Pendahuluan}

Negara berkewajiban mencerdaskan kehidupan bangsa sebagai amanah dari Pembukaan Undang-Undang Dasar Tahun 1945. Amanat konstitusi ini mengisyaratkan bahwa hanya bangsa 
yang cerdas yang mampu dan bersaing dengan bangsa-bangsa di dunia. Oleh karena itu peningkatan kualitas Sumber Daya Manusia di setiap negara menjadi sebuah keniscayaan.

Pendidikan adalah salah satu pilar kehidupan bangsa. Masa depan suatu bangsa bisa diketahui melalui sejauh mana komitmen masyarakat, bangsa atau pun negara dalam menyelenggarakan Pendidikan Nasional. Oleh karena itu, pendidikan menjadi faktor utama atau penentu bagi masa depan bangsa. ${ }^{1}$ Adapun tujuan pendidikan nasional adalah mencerdaskan kehidupan bangsa, mengembangkan prestasi peserta didik agar menjadi manusia yang beriman, bertaqwa kepada Tuhan Yang Maha Esa, berakhlak mulia, memiliki pengetahuan dan keterampilan, kreatif, mandiri, sehat jasmani dan rohani dan menjadi warga negara yang demokratis dan bertanggung jawab. ${ }^{2}$

Mutu pendidikan yang menyangkut berbagai komponen sebagai satu kesatuan . oleh karena nya dalam peningkatan mutu pendidikan tidak boleh hanya melihat pada satu sisi saja. Peningkatan mutu pendidikan harus dilihat dari unsur input, proses dan output. Menurut Departemen Pendidikan Nasional ada beberapa faktor rendahnya mutu pendidikan di Indonesia meliputi: Kebijakan dam penyelenggaraan pendidikan nasional menggunakan pendekatan educational prodaction fuction/ input output analysis yang tidak dilaksanakan secara konsekuen; (2) Penyelenggaraan pendidikan nasional dilakukaan secara birokratik, sentralistik, sehingga menempatkan sekolah sebagai penyelenggara; (3) Peran serta masyarakat, khusunya orang tua siswa dalam penyelenggaraan pendidikan selama ini sangat minim partisipasi masyarakat.

Penyelenggaraan sistem pemerintahan di Indonesia telah berimbas pada pengelolaan sistem pendidikan, yakni yang semula lebih bersifat sentralistik bergeser kearah desentralistik. Yang mana dinyatakan secara implisit. ${ }^{3}$ Dengan harapan dapat melaksanakan kewajiban dan bertanggung jawab dan dapat memberikan manfaat yang sebesar-besarnya bagi penduduk daerah. Dalam hal ini pada bidang pendidikan untuk dapat menerapkan strategi yang tepat dalam pengelolaan pendidikan. Yakni adanya kerjasama yang erat antara sekolah, masyarakat dan pemerintah. Untuk itu sekolah harus dapat memahami kondisi lingkungan (kelebihan dan kekurangan) untuk kemudian melalui proses perencanaan dalam bentuk program-program prioritas yang harus dilaksanakan dan dievalusi sesuai dengan visi dan misinya. Sekolah harus menentukan target mutu yang ingin dicapai untuk setiap kurun waktu, merencanakannya, melaksanakan dan mengoreksi untuk kemudian menentukan target mutu untuk tahun berikutnya. Dengan demikian sekolah dapat mandiri tetapi masih dalam rangka acuan kebijakan nasional.

Peningkatan mutu pendidikan harus dilaksanakan dengan memberdayakan dan melibatkan semua unsur yang ada dilembaga pendidikan. Adanya penerapan sistem otonomi daerah dalam

\footnotetext{
${ }^{1}$ Mu'arif, Wacana Pendidikan Kritis (Jogjakarta: IRCiSoD, 2005), 89.

2 Undang-Undang Nomor 22 Tahun 2003 Tentang Sistem Pendidikan Nasional Pasal 3

3 Undang-Undang Nomor 22 Tahun 1999 Tentang Pemerintah Daerah
} 
Pemerintahan, sebagaimana UU Nomor 2 Tahun 1999 disebutkan disebutkan adanya pelimpahan wewenang oleh pemerintah pusat kepada pemerintah daerah dalam kerangkan negara kesatuan Republik Indonesia. Pelimpahan wewenang dari pusat ke daerah, termasuk didalamnya pendidikan. Pengeloaan khusus dibidang pendidikan yang dikenal dengan otonomi pendidikan adalah melatarbelakangi penerapan manajemen berbasis sekolah pada setiap lembaga pendidikan. Dengan penerapan demokrasi pendidikan ini dalam kerangka manajemen berbasis sekolah, masing-masing lembaga dihadapkan dengan berbagai masalah dan tuntutan seiring perkembangan disegala bidang. Yaitu sekolah diberikan otonomi yang lebih besar dalam kewenangan dan pengelolaan dengan menerapkan keputusan partisipasif, dalam rangka meningkatakan mutu pendidikan berdasarkan kebijakan pendidikan nasional.

Dengan diberlakukannya paradigma baru ini memungkinkan sekolah memiliki otonomi yang seluas-luasnya, yang menuntut peran masyarakat secara optimal, dan menjamin kebijakan nasional yang terabaikan. Selama ini masyarakat sebagai bagian tak terpisahkan dari pengelolaan pendidikan seringkali hanya bersifat "pelengkap". Sekolah yang merupakan "kepanjangan tangan" pemerintah seringkali meletakkan dan memposisikan masyarakat sebagai pendukung kebijakan sekolah. Karena itu peran masyarakat yang mestinya sejajar dengan sekolah, tidak tampak. Bahkan masyarakat dimarjinalkan karena dianggap sebagai pelengkap belaka ${ }^{4}$.

Akan tetapi dengan paradigma baru ini, sekolah sebagai lembaga pendidikan terdepan memiliki wewenang yang besar dalam mengelola dan menentukan arah pertumbuhan dan perkembagan lembaganya. Selain itu, dengan MPMBS peran serta masyarakat menduduki tempat yang urgent karena disini sekolah dituntut untuk mandiri walaupun masih harus mengacu pada kebijakan atau acuan yang telah ditetapkan oleh pemerintah (tujuan pendidikan nasional). Masyarakatlah yang tahu persis apa yang menjadi kebutuhannya dan apa yang diharapkannya dari generasi muda di masa mendatang. Disamping itu, setiap masyarakat mempunyai budaya dan adat istiadat yang beranekaragam, sehingga antara masyarakat yang satu dengan yang lainnya mempunyai kebutuhan yang berbeda.

Kepala sekolah merupakan faktor penggerak, penentu arah kebijakan sekolah yang akan menentukan bagaimana tujuan sekolah dan pendidikan pada umumnya yang direalisasikan dengan MPMBS. Kepala sekolah dituntut senantiasa meningkatkan efektifitas kinerja. Dengan begitu, MPMBS sebagai paradigma baru pendidikan yang dapat memberikan hasil yang memuaskan. Kinerja kepala sekolah dalam kaitannya dengan MPMBS adalah segala upaya yang dilakuakan dan

\footnotetext{
${ }^{4}$ Supriono S. Dan Achmad Sapari, Manajemen Berbasis Sekolah (Jabang Jatim: Anggota IKAPI, , 2001), 66.
} 
hasil yang dapat dicapai oleh kepala sekolah dalam mengimplementasikan MPMBS disekolahnya untuk mewujudkan tujuan pendidikan secara efektif dan efisien.

Melihat penting dan strategisnya posisi kepala sekolah dalam mewujudkan tujuan sekolah, maka seharusnya kepala sekolah harus mempunyai nilai kemampuan relation yang baik dengan segenap warga di sekolah, sehingga tujuan sekolah dan tujuan pendidikan berhasil dengan optimal. Ibarat nahkoda yang menjalankan sebuah kapal mengarungi samudra, kepala sekolah mengatur segala sesuatu yang ada di sekolah.

Dari uraian diatas peneliti ingin mencermati SMPN 13 Malang, di sini peneliti ingin mengamati bagaimana sosok peran kepala sekolah sebagai tokoh sentral di lingkungan pendidikan. Karena dengan adannya otonomi daerah kepala sekolah mempunyai kewenangan keputusan pertisipatif dalam memandirikan dan memberdayakan sekolah. Oleh karena itu peneliti merasa interst, bagaimana kepala sekolah mengaktualisasikan MPMBS di sekolahnya.

\section{Metode Penelitian}

Peneltian ini menggunakan pendekatan kualitatif ${ }^{5}$ dengan studi kasus di SMPN 13 Malang. Sumber data pada penelitian ini terdiri dari: sumber data primer dengan informan: kepala sekolah, wakil kepala sekolah, waka. kurikulum, guru agama, kepala TU, dan komite sekolah. Sedagkan sumber data sekunder yang terdiri dari dokumen-dokumen struktur organisasi, dokumen tupoksi dan tugas tambahan.

Teknik pengambilan data menggunakan tiga teknik, yakni observasi, wawancara, dan dokumentasi. Setelah mendapatkan data di lapangan, tahapan selanjutnya adalah proses reduksi data, penyajian data, dan kemudian verifikasi data. Sedangkan metode analisis data dalam penelitian ini adalah dengan menggunakan metode analisis deskripsi.

\section{Temuan dan Pembahasan}

\section{Peran Kepala Sekolah Sebagai Manajer}

Kepala sekolah adalah manejer pendidikan tingkat sekolah dan ujung tombak utama dalam mengelola pendidikan di level sekolah. Kepala sekolah memegang peran poros yang paling penting (privotal role) untuk keberhasilan aktualisasi MPMBS, dan oleh karena itu, kepala sekoah harus mempunyai kemampuan manajerial yang professional dalam mengelola sekolahnya. ${ }^{6}$

Kemampuan manjerial SMPN 13 Malang dapat ditunjukkan dengan, membuat perencanaan peningkatan mutu sekolah, yang dalam pelaksanaan melibatatkan semua elemen s ekolah mulai dari

\footnotetext{
${ }^{5}$ Bogdam dan Taylor Mendefinisikan metode kualitatif sebagai prosedur penelitian yang menghadirkan data deskriptif beberap kata-kata tertulis atau lisan dari orang-orang atau pelaku yang dapat diamati. Baca Lexy J. Moeloeng, Metodologi Penelitian Kualitatif (Bandung: Remaja Rosdakarya, 2000), 3.

${ }^{6}$ Hadiyanto, Mencari Sosok Desentralisasi Manajemen Pendidikan Dini Indonesia, . (Jakarta: Rineka Cipta, 2004), 55.
} 
wakil kepala sekolah, guru, pawa wakil kepala sekolah, koordinator TU, serta komite sekolah. Hal ini sesuia dengnan konsep dari MPMBS yang menuntut dukungan semua pihak, partisipasi masyarakat dan orang tua yang merupakan salah satu aspek peningkatan mutu sekolah. Kepala sekolah juga sudah menetapkan para truktur organisasi sekolah beserta struktur administarsi sekolah beserta tugasnya pula. Hal ini untuk mempermudah pengevaluasian sekolah.

Salah satu arahan dalam menggerakkan guru dan staff adalah dengan menerapkan motivasi Artinya kepala sekolah harus dapat mendorong agar para guru dan staff termotivasi untuk mengerjakan tugasnya. Cara yang dilakukan kepala sekolah adalah menggerakkan guru dan staff dalam organisasi sekolah untuk bekerja secara optimal. Dan menggerakkan pihak eksternal sekolah yaitu komite sekolah yang sebagai partner sekolah dalam melaksnakan peningkatan mutu sekolah.

Dan evaluasi menganai program peningkatan mutu sifatnya 3 bulan sekali. Dan pada waktu tertentu yang memang membutuhkan kehadiran dewan sekolah kita bisa mendatangkan, karena kami lihat peran dewan sekolah dalam peningkatan mutu sekolah ini sangat urgen. Kepala sekolah beserta dewan sekolah biasanya mengadakan musyawarah terlebih dahulu topik yang disamapaikan adalah mengenai permasalah misalnya saja Program IMTAQ siswa. Karena dalam program ini dewan sekolah sangat mendukung, sehingga kalau ada permasalahan maka kita minta solusi yang terjitu”.

\section{Peran Kepala Sekolah Sebagai Pendidik}

Salah satu faktor yang paling menentukan berhasilnya proses belajar mengajar dalam kelas adalah guru. Karena itu guru tidak saja mendidik melainkan juga berfungsi sebagai orang dewasa yang bertugas professional memindahkan ilmu pengetahuan (taransfer of knowledge) atau penyalur ilmu pengetahuan (transmitter of knowledge) yang dikuasai kepada anak didik. Guru menjadi pemimpin, atau menjadi pendidik, dan pembimbing di kalangan anak didiknya. ${ }^{7}$

Kepala sekolah SMPN 13 telah melakukan usaha peningkatan kualitas guru yang merupakan keharusan dalam proses belajar mengajar agar dapat mencapai tujuan pengjarannya. Usaha kepala sekolah dalam meningkatkan kualitas guru antara lain: mengadakan pelatihan, mengikuti seminar, diadakannya MGMP di sekolah, dan menghadiri MGMP yang diadakan DIKNAS setiap satu bulan sekali.

Pelaksanaan MPMBS di SMPN 13 Malang, bisa dikatakan sukses dengan program unggulan Marching Bandnya. Karena sekolah yang telah melaksanakan MPMBS harus mampu mengatarkan peserta didik mempunyai skill atau keterapilan yang akan membantu untuk keberlangsungan hidupnya. Maka kepala sekolah membuka program ekstarkulikuler yang memadai untuk

\footnotetext{
${ }^{7}$ Muzayyin Arifin, Kapita Selekta Pendidikan Islam (Jakarta Bumi Aksara, 2003), 118.
} 
pengembangan bakat dan minat siswa, mulai dari yang bersifat ilmu pengetahuan misalnya karya ilmiah remaja (KIR), conversation program dari pengembangan mata pelajaran bahasa inggris, IMTAQ yaitu dengn tujuan peningkatan keimanan siswa serta diharapkan dapat berahlak muli. Biding non edukatif seperti ekstra kurikuler karate, seni tari, komputer, KIR, dan tata boga, marching band terlaksana penuh dengan prestasi yang baik, keberhasilan kepala sekolah mewujudkan program ini terbukti dengan diraihnya kejuaraan.

\section{Peran Kepala Sekolah Sebagai Supervisor}

Supervisi ialah aktivitas pembinaan yang direncanakan untuk membantu para guru dan pegawai sekolah dalam pekerjaan mereka secara efektif. Adapun yang sudah dilakukan kepala sekolah di SMPN 13 Malang sebagai supervisor dalam aktualisasi MPMBS membuat perencanaan pembelajaran dan program supervisi kegiatan problem solving dengan koordinator guru pembimbing. Dalam pelaksanaan supervisior kepala sekolah, berusaha mengurangi permasalah guru dalam meningkatkan proses belajar mengajar.

Perlu dipahami bahwa setiap kepala sekolah bertanggungjawab mengarahkan apa yang baik bagi tenaga kependidikan, dan dia sendiri harus berbuat baik. Kepala sekolah juga harus menjadi contoh, sabar dan penuh pengertian. Seperti motto Ki Hajar Dewantara: Ing ngarsa sung tulada, Ing madya mangun karsa, Tut wuri handayaniKemampuan melakukan pengawasan dan pengendalian untuk meningkatkan kinerja tenaga kependidikan. ${ }^{8}$

Kepala sekolah sebagai supervisor merupakan salah satu faktor yang dapat mendorong peningkatan guru dalam peroses belajar mengajar, dalam program peningkatan mutu sekolah kepala sekolah telah melaksanakan tugasnya dengan baik, yaitu bisa meningkatkan kualitas gurunya agar dalam pelaksanaan program yang sudah disepakati bersama bisa terlaksana dengan baik. Program unggulan SMPN 13 Malang dalam Marching Band telah dipersiapkan pelaksanaannya dalam pementasan di Bali nanti, sehingga bisa menghasilkan yang memuaskan. Karena fungsi utama supervisi adalah perbaikan proses pembelajaran agar peserta didik dapat menyerap secara maksimal segala pesan yang disampaikan guru.

Teknik yang digunakan kepala sekolah SMPN 13 Malang dalam pelaksanaan supervise, yaitu dengan individual dan kelompok. Yaitu membimbing guru dalam mengatasi probema siswa dan dan dalam kelompok membicarakan proses dalam belajar mengajar.

Secara praktek kepala sekolah telah melaksanakan tugasnya sebagai supervisor yang matang, sesuai dengan teknik-teknik supevisi, yaitu perseorangan dan kelompok. Teknik perseorangan dapat dilakukan dengan: a. mengadakan kunjungan kelas, b. mengadakan kunjungan observasi, c. membimbing guru tentang mempelajari siswa dan atau menngatasi problema yang dialami siswa,

\footnotetext{
${ }^{8}$ E. Mulyasa, Menjadi Kepala Sekolah Profesional (Bandung: Remaja Rosdakarya, 2004), 122
} 
membimbing guru dalam pelaksanaan kurikulum, sedangkan teknik kelompok dapat dilakukandengan: a. mengadakan pertemuan atau rapat, b. mengadakan diskusi kelompok, c. mengadakan penataran.?

\section{Peran Kepala Sekolah Sebagai Pemimpin}

Figur kepala sekolah di era peningkatan mutu sekolah dibutuhkan pemimpin yang mampu meningkatkan mutu sekolah. Apalagi dengan diberlakukannya otonomi sekolah maka kepala sekolah sebagai nahkoda di sekolahnya harus mampu mengambil keputusan yang cerdas tidak merugikan dan menguntungkan sebelah pihak semata. Karena konsep manajemen ini menggariskan bahwa manajemen sekolah sangat ditentukan oleh kemampuan pemimpin dalam membuat keputusan-keputusan yang bermutu yang diperoleh melalui langkah-langkah yang sistematis. ${ }^{10}$

Hal itu sudah dilaksanakan oleh kepala sekolah SMPN 13 Malang sebagai sosok pemimpin yang arif dan bijaksana karena dalam memutuskan perkara yang ada dalam sekolah SMPN 13 senantiasa melalui musyawarah yang diikuti oleh para dewan guru dan juga melibatkan komite sekolah jika ada yang bersifat insidental.

Selain itu kepala sekolah juga telah melaksanakan tugas sebagai pemimpin sekolah dengan mengikuti dan mendukung dan memotivasi terhadap program yang kita laksanakan, misalnya pada waktu pelaksanaan sholat berjama'ah kepala sekolah memberi siaraman rohani kepada segenap dewan guru dan para. Kepala sekolah selalu mengatakan bahwasanya pekerjaan guru adalah hal yang mulia. Kepala sekolah, sering mengacungkan jempol dan memberi semangat kepada guru yang telah melaksanakan tugasnya dengan baik. Saya bisa memberi contoh, progarm 2005 ini ada IMTAQ yang memang dirilis tahun ajaran sekarang, kepala sekolah senantiasa memberi semangat kepada Bpk. Baidhowi dengan menyakinkan dan memberi ide agar program yang baru ini bisa terealisasi dengan maksimal".

\section{Kesimpulan}

Implementasi MPMBS di SMPN 13 Malang sudah optimal sebagaimana data dan pembahasan di atas. Hal tersebut bisa dilihat dari pemahaman kepala sekolah dalam aktualisasi MPMBS. Kepala sekolah sebagai direktur sekolah telah mensosialisaikan ke segenap warga sekolah, mulai dari guru, staf, karyawan, siswa sera wali murid. Kepala sekolah telah melakukan program unggulan/khusus untuk meningkatkan potensi siswa dengan dengan mengadakan program IMTAQ dan handalan

\footnotetext{
${ }^{9}$ Ngalim Purwanto, Supervisi Pendidikan (Bandung: Remaja Rosdakarya, 1990), 122.

10 Sudarwan Danim, Visi baru Manajmen Sekolah (Jakarta: PT Bumi Aksara, 2006), 229.
} 
SMPN 13 yaitu Marching Band. Kepala sekolah juga melibatkan orang tua dalam aktualisasi MPMBS, karena sekolah merupakan partner orang tua dalam mengantarkan cita-cita dan membentuk pribadi peserta didik. Kepala sekolah juga membuat iklim sekolah dengan hidup disiplin. Karena dengan hidup disiplin, maka ada rasa hormat terhadap kewenangan, hormat terhadap orang lain serta upaya untuk menanamkan kerjasama.

Terkait peran kepala sekolah SMPN 13 Malang dalam aktualisasi MPMBS telah memainkan peran-perannya diantaranya sebagai manager, pendidik, supervisior, pemimpin. Dalam mengatur sekolah, kepala sekolah telah membuat perencanaan peningkatan mutu sekolah sesuai dengan visi misi sekolah, mengorganisasikan penetapan penanggungjawab, dan menggerakkan warga (guru dan karyawan) sekolah dalam peningkatan mutu sekolah, serta mengawasi pelaksanaan peningkatan mutu sekolah. Dan di SMPN 13 Malang juga mengadakan evaluasi 3 bulan sekali. Sebagai pendidik,

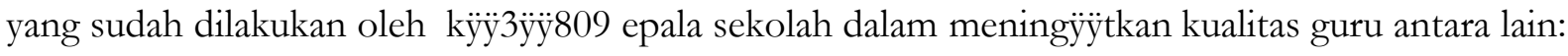
mengadakan pelatihan, mengikuti seminar, diadakannya MGMP di sekolah, dan menghadiri MGMP yang diadakan DIKNAS. Dan dalam meningkatkan prestasi pserta didik, manambah jam pelajaran, mengadakan try out, serta membuka program ekstrakulikuler yang memadai untuk pengembangan bakat dan minat siswa, mulai dari yang bersifat ilmu pengetahuan misalnya karya ilmiah remaja (KIR), conversation program dari pengembangan mata pelajaran bahasa inggris, IMTAQ. Bidang non edukatif seperti ekstrakurikuler karate, seni tari, komputer, dan tata boga, marching band. Sebagai supervisior kepala sekolah telah melakukan pengawasan dan pengendalian untuk meningkatkan kinerja tenaga kependidikan dalam melaksanakan program yang telah disepakti bersama. Kepala sekolah juga berusaha mengatasi permasalahan guru dengan baik, baik hal menggunakan teknik individual maupun kelompok. Kepala sekolah sebagai seorang pemimpin dalam mengambil keputusan kegiatan-kegiatan sekolah, melibatkan segenap dewan guru dan komite sekolah. Dalam pelaksanaan kegiatan sekolah kepala sekolah juga memberi motivasi ke segenap koordinator pelaksana kegiatan, hal ini menunjukkan bahwasanya adanya dukungan dari kepala sekolah

\section{Daftar Kepustakaan}

Arifin, Muzayyin Kapita Selekta Pendidikan Islam. Jakarta Bumi Aksara, 2003.

Danim, Sudarwan Visi baru Manajmen Sekolah. Jakarta: PT Bumi Aksara, 2006.

Hadiyanto, Mencari Sosok Desentralisasi Manajemen Pendidikan Dini Indonesia. Jakarta: Rineka Cipta, 2004.

Moeloeng, Lexy J. Metodologi Penelitian Kualitatif. Bandung: Remaja Rosdakarya, 2000. 
Mu'arif, Wacana Pendidikan Kritis. Jogjakarta: IRCiSoD, 2005.Mulyasa, E. Menjadi Kepala Sekolah Profesional. Bandung: Remaja Rosdakarya, 2004.

Purwanto, Ngalim Supervisi Pendidikan. Bandung: Remaja Rosdakarya, 1990.

Undang-Undang Nomor 22 Tahun 2003 Tentang Sistem Pendidikan Nasional Pasal 3

Undang-Undang Nomor 22 Tahun 1999 Tentang Pemerintah Daerah

S. Supriono dan Achmad Sapari, Manajemen Berbasis Sekolah. Jabang Jatim: Anggota IKAPI, , 2001. 